\title{
Feminization of hawksbill turtle hatchlings in the twenty-first century at an important regional nesting aggregation
}

\author{
Mark Chatting, Shafeeq Hamza, Jassim Al-Khayat, David Smyth, Sinan Husrevoglu, Christopher D. Marshall
}

\begin{abstract}
Projected climate change is forecasted to have significant effects on biological systems worldwide. Marine turtles in particular may be vulnerable, as the sex of their offspring is determined by their incubating temperature,. This study aimed to estimate historical, and forecast future, primary sex ratios of hawksbill turtle, Eretmochelys imbricata, hatchlings in Qatar. Incubation temperatures were measured over 2 nesting seasons. Climate data from same period were regressed with nest temperatures to estimate incubation temperatures and hatchling sex ratios for the site from 1993 to 2100 . Historical climate data showed female-biased sex ratios of $73.2 \pm 12.1 \%$ from 1993 to 2017 . Female biases from 2018 to 2100 averaged $85.7 \% \pm 6.7 \%$. In addition, predicted female hatchling production was $>90 \%$ from 2054 . These results show that hawksbill primary sex ratios in Qatar are at risk of significant feminization by the year 2100 .
\end{abstract}

Introduction: Marine turtles are at particular risk from climate change since hatchling sex is determined by their incubation temperature. Forecasted climate change in the is likely to induce significant increases in incubation temperatures, causing sex ratios to skew. Previous research has predicted hatchling sex ratios using climate data. The Arabian Gulf is an extreme environment in which hawksbill turtles Eretmochelys imbricata nest. As such, extreme temperatures may already be skewing primary sex ratios, and climate change is likely to pose a serious threat to marine turtles in the Arabian Gulf throughout the 21st century. This study aimed to predict hatchling sex ratios from 1993 to 2100 in Qatar.
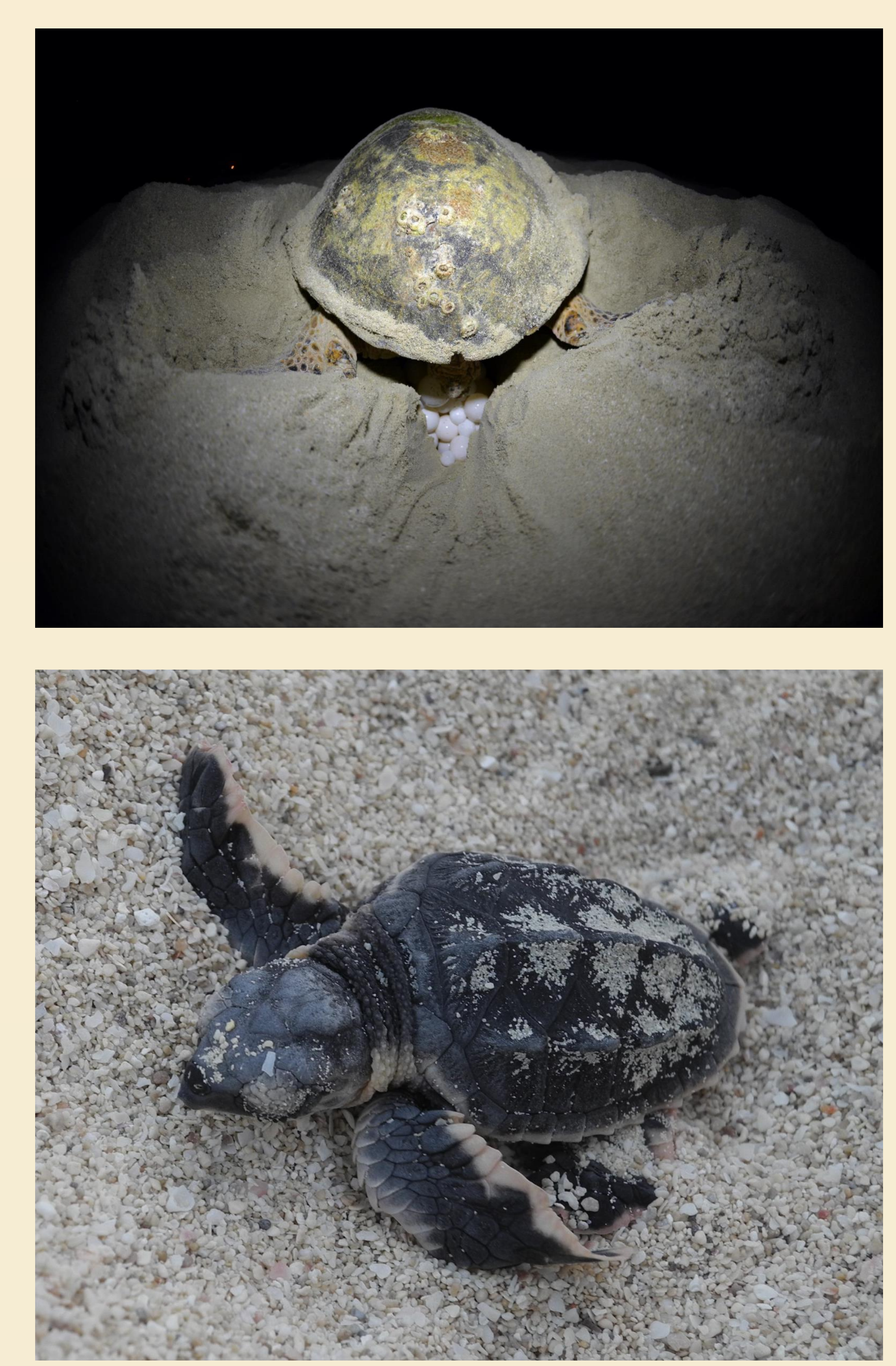

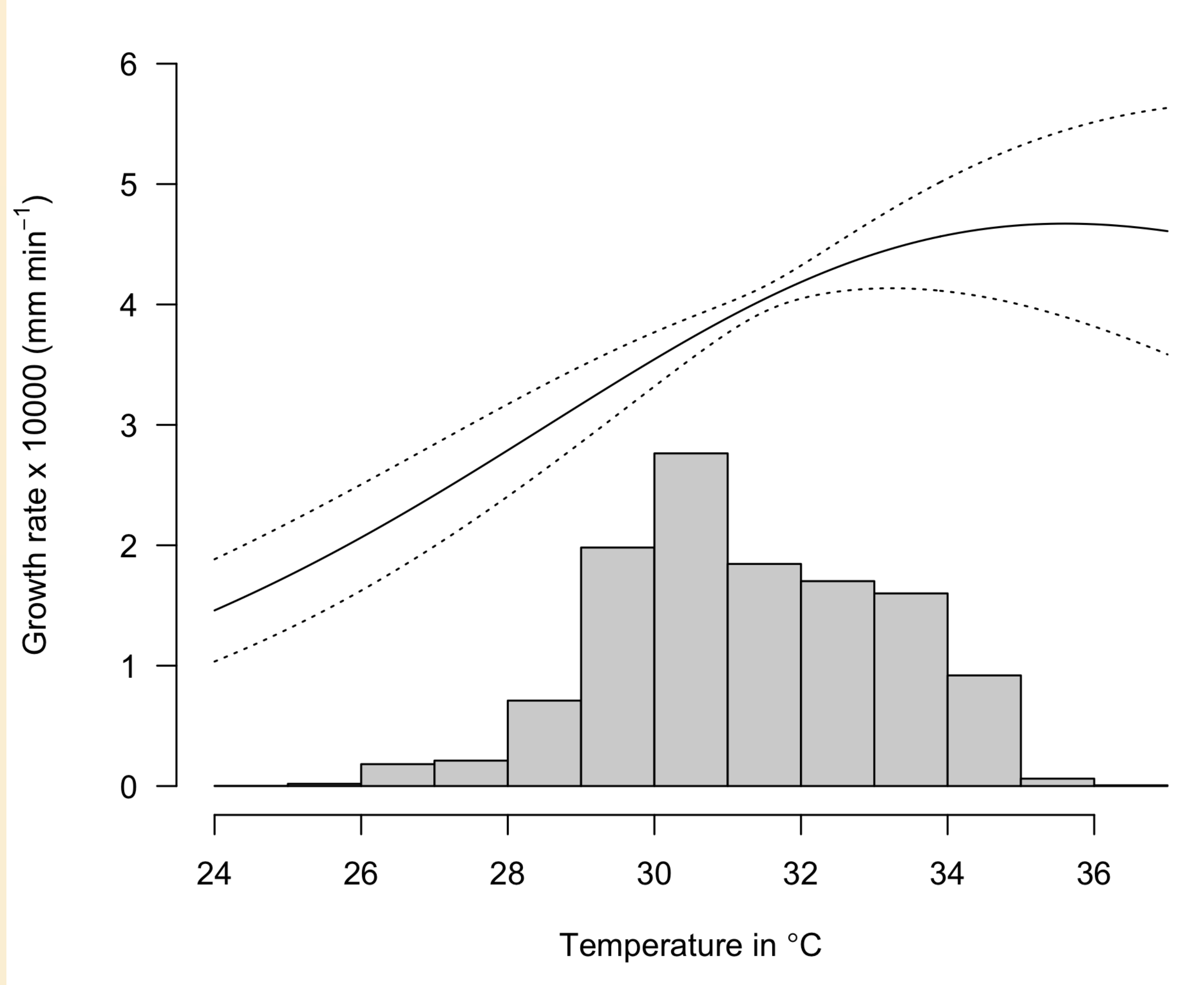

Fig. 1: Thermal reaction norm exhibited by hatchlings in Qatar

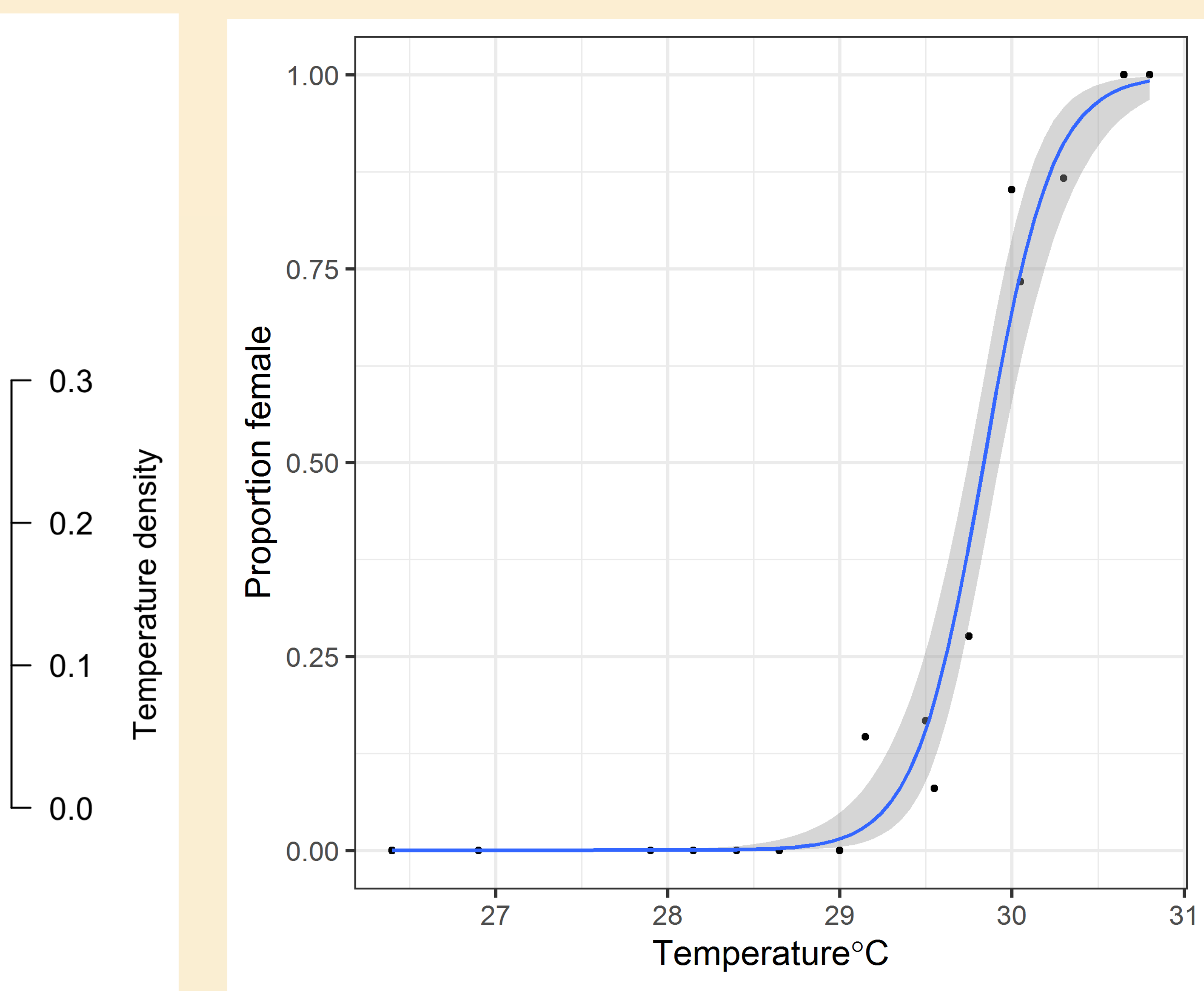

Fig. 2: Model to predict female proportion of a clutch
Methods: Nesting site incubation temperatures were measured along the northeastern coast of Qatar in the 2016 and 2017 nesting seasons. Recorded incubation temperatures were regressed with climate data based on a previously published method (Monsinjon et al. 2017). Sex of marine turtle hatchlings is determined in the middle third of development, which is termed the thermosensitive period (TSP) (Girondot 1999). It was assumed that the timing and distribution of the annual nesting period remained the same each year from 1993 to 2100 . A logistic regression predicted sex ratio from modelled TSP's to determine the proportion of each clutch that was female from 1993 to 2100.

Results: The thermal reaction norm exhibited by hawksbills in Qatar showed an increase in embryonic growth rate up to $35.1^{\circ} \mathrm{C}$, after which the rate decreased (Fig. 1). The logistic model used to predict proportion female from TSP incubation temperature showed a PT of $29.6^{\circ} \mathrm{C}$ and a transitional temperature zone from 28.6 to $30.8^{\circ} \mathrm{C}$ (Fig. 2). A significant female bias was detected throughout the entire study period (1993-2100) (Fig. 3). Female production from 1993-2017 was 73.2 $\pm 12.1 \%$. Over $90 \%$ annual female hatchling production occurred regularly by 2054 and was predicted to occur in 41 out of 107 years (38.3\%).

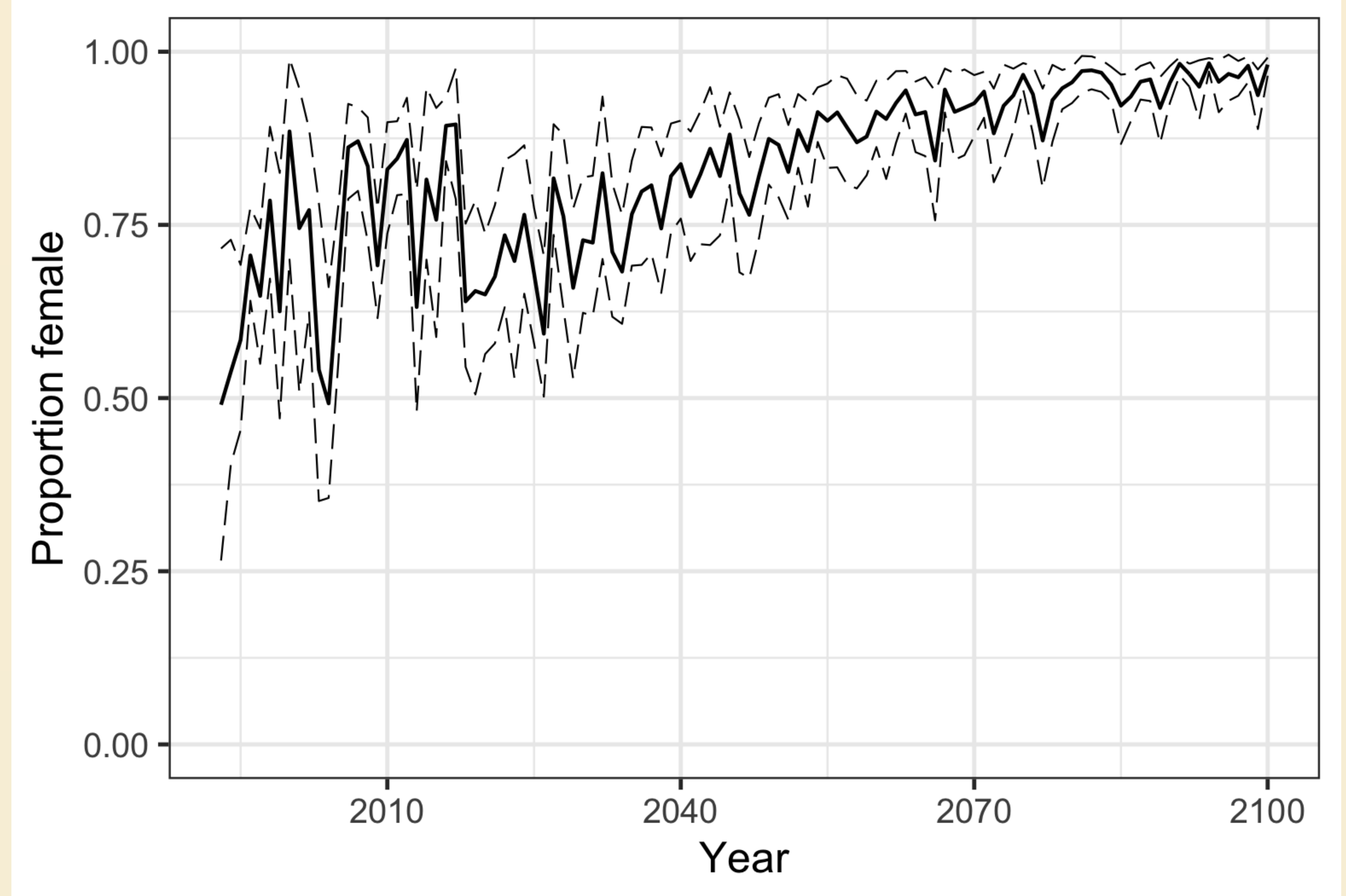

Fig. 3: Modelled annual female production in Qatar

Discussion: Results from this study predict a significant increase in the proportion of female hatchlings produced in Qatar in the $21^{\text {st }}$ century, an important nesting ground in the Gulf. These results support other predictive studies forecasting significant feminization of primary sex ratios in marine turtle species around the world (Patrício et al. 2019). An almost 'complete feminization' of green turtles, Chelonia mydas, in the northern Great Barrier Reef has been predicted (Jensen et al. 2018). This study may allow conservationists to track future primary sex ratios and may help detect extreme sex ratio biases, to further inform conservation actions.

Reference

Girondot M (1999) Statistical description of temperature-dependent sex determination using maximum likelihood. Evol Ecol Res 1:479 486.

One of the Largest Sea Turtle Populations in the World. Curr Biol 28:154-159.e4.

Monsinjon J, Jribi I, Hamza A, Ouerghi A, Kaska Y, Girondot M (2017) Embryonic Growth Rate Thermal Reaction Norm of Mediterranea Caretta caretta Embryos from Two Different Thermal Habitats, Turkey and Libya. Chelonian Conserv Biol 16:172-179.

Patrício AR, Varela MR, Barbosa C, Broderick AC, Catry P, Hawkes LA, Regalla A, Godley BJ (2019) Climate change resilience of a globall important sea turtle nesting population. Glob Chang Biol 25:522-535. 